\section{Leptin instead of insulin}

\section{By Lev Osherovich, Senior Writer}

Texas researchers have shown that the fat-derived hormone leptin could substitute for insulin to control blood sugar fluctuations in patients with type 1 diabetes. ${ }^{1}$ The work has caught the attention of Amylin Pharmaceuticals Inc., which is now collaborating with the researchers to set up a Phase II trial of this new therapeutic approach.

Ordinarily, insulin secreted by pancreatic islet $\beta$ cells after a meal prompts liver and muscle cells to convert excess blood sugar to glycogen. In type 1 diabetes, loss of these $\beta$ cells from autoimmune attack leaves patients without a way to control high blood sugar; over time, this leads to kidney and cardiovascular damage.

Insulin replacement has been the standard of care for type 1 diabetes since the 1920s, when the hormone's role in regulating sugar uptake from the bloodstream was discovered. But inaccurate dosing of injected insulin can lead to dangerous fluctuations in blood sugar, making continuous blood sugar monitoring and regular high-dose insulin injections a necessity for diabetics.

Roger Unger, professor of internal medicine at The University of Texas Southwestern Medical Center at Dallas, and his team may have found an alternative to insulin.

In a study published in the Proceedings of the National Academy of Sciences, the team showed that in a mouse model of type 1 diabetes, the adipocyte-derived hormone leptin was as effective as insulin in controlling blood sugar while eliciting fewer undesirable side effects.

Leptin signaling in the brain had previously been implicated in appetite and weight control, but the effect of leptin on blood sugar has only recently been discovered.

"The dogma that we've grown up with since the discovery of insulin-that insulin is the only way to reverse the consequences of insulin deficiency-is not entirely true," Unger told SciBX. "We can reverse the metabolic consequences of insulin deficiency with leptin."

Jay Skyler, professor of medicine, pediatrics and psychology at the University of Miami, said Unger's study "opens the door" to a new approach for treating type 1 diabetes. Skyler is on Amylin's board of directors but told SciBX that he was not speaking on behalf of the company.

"Leptin has been thought of as a hormone that helps modulate energy expenditure and weight control by signaling adipose mass to the brain," said Skyler. "But studies such as this one show that leptin is also playing a role in glucose metabolism."
David Maggs, VP of R\&D strategic relations at Amylin, added that Unger's findings "change the lens on how to look at type 1 diabetes" and offer hope of an alternative to high-dose insulin therapy.

In a typical treatment regimen, "insulin delivery is nonphysiological," said Maggs. "Sometimes there's too much or too little, resulting in blood glucose fluctuations. Even patients with good glycemic control on insulin therapy still have glucose fluctuations that are fairly life disrupting. If Unger is correct that leptin allows you to reduce insulin utilization, you might reduce the blood glucose fluctuation as well."

"There have been umpteen things shown to prevent type 1 diabetes in mice, but very few things that control the disease once it has set in," said Skyler. "Here we see very dramatic effects. I'm very excited about this work."

\section{Better control}

Drawing from earlier studies with leptin transgenic mice that showed changes in glucose metabolism, ${ }^{2}$ Unger's team tested the effect of subcutaneous leptin in nonobese diabetic mice, a standard model for type 1 diabetes.

Compared with insulin-treated mice, leptin-treated mice showed similar reductions in blood sugar and similar metabolic fingerprints of hyperglycemia such as glucose and ketones in the urine. The team also found that combining low doses of leptin and insulin led to steadier long-term blood glucose control than high doses of insulin alone, suggesting that leptin could be used as an adjunct to conventional insulin therapy.

Unger's team also found that leptin had a more benign effect on diet and lipid metabolism. Leptin-treated mice had less food intake and lower levels of fatty acids and cholesterol biosynthetic enzymes than insulin-treated controls.

Unger thus thinks that leptin could be useful for preventing dyslipidemia, a common side effect of long-term insulin treatment that leads to obesity and cardiovascular complications in many patients.

"It's almost the rule that if you live long enough on insulin therapy, you'll have heart disease" due to insulin's effects on cholesterol and fatty acid synthesis, he said. Because leptin suppresses appetite, using it as treatment could make it easier to comply with the diets often prescribed to control blood sugar fluctuation in diabetics, Unger added.

\section{Mechanistic questions}

Although Unger's findings are intriguing, the mechanism by which leptin substitutes for insulin is far from clear, said Rohit Kulkarni, an investigator at the Joslin Diabetes Center.

In 2008, Kulkarni's team reported both that pancreas-specific leptin receptor (LEPR; CD295; OBR) knockout mice had higher insulin levels than control mice and that altered leptin activity contributes to type 2 diabetes. ${ }^{3}$ However, Kulkarni told SciBX that the strong hyperglycemia-countering effects of leptin described by Unger's team still come as a surprise. 
Still, although the UT Southwestern researchers showed "nice data in a clean model," Kulkarni said the findings will need to be reproduced by other researchers and in other type 1 diabetes models before being widely accepted.

Learning where and how leptin acts will be critical, he added.

Unger thinks the antidiabetic effects of leptin are a consequence of the hormone's action on pancreatic $\alpha$ cells, which secrete glucagon. Glucagon counteracts the effect of insulin by stimulating the conversion of glycogen to blood sugar. Ordinarily, insulin suppresses the production of glucagon, but without insulin inhibition, glucagon steadily rises, leading to further hyperglycemia.

Indeed, Unger's team found that either leptin or insulin treatment lowered glucagon in diabetic mice compared with mock treatment.

He noted that suppressing glucagon production in the pancreas requires very high systemic doses of insulin, much more than the dose needed to regulate blood sugar in the liver and muscles.

"The rationale for using leptin is that it suppresses glucagon just as well as insulin does" but requires lower concentrations of insulin to achieve the same effect, said Unger. Controlling glucagon levels with leptin "does the heavy lifting, which means that you just need enough insulin in the periphery for normal glycemic control."

However, Kulkarni noted that studies by his own team and other groups have found no evidence of leptin receptors in pancreatic $\alpha$ cells, so the effects on glucagon observed by Unger could result from leptin's action on other tissues.

Kulkarni also cautioned that treating type 1 diabetes with leptin itself may elicit undesirable CNS effects on appetite and libido, and he added that small molecule agonists of LEPR that don't cross the blood brain barrier may be more attractive as potential therapeutic agents.

Meanwhile, University of Miami's Skyler wants to see further experiments to determine whether leptin can control glucose fluctuations over longer periods.

Amylin is developing leptin receptor agonists as antiobesity thera- peutics after the company acquired patents and development rights to leptin analogs from Amgen Inc. in 2006. Amylin and Takeda Pharmaceutical Co. Ltd. have completed Phase II obesity trials of a combination of the leptin analog metreleptin and pramlintide, an analog of the appetite-suppressing hormone amylin.

Amylin also markets Symlin pramlintide as an adjunct to insulin to control glucose in type 1 diabetes.

Despite uncertainty about leptin's mechanism in type 1 diabetes, Amylin's Maggs thinks the robustness of Unger's preclinical data makes the leptin approach "worth following up with a clinical trial."

Unger told SciBX that because leptin analogs have thus far proven safe, he is ready to launch a Phase II trial of leptin receptor agonists as an adjunct to insulin therapy. He is collaborating with Amylin, which is contributing its leptin analog for the trial.

Amylin said it is in discussions with UT Southwestern regarding a licensing agreement for patents filed on Unger's discoveries. According to the university, a patent is pending on the findings described in PNAS and is available for licensing.

Osherovich, L. SciBX 3(10); doi:10.1038/scibx.2010.296

Published online March 11, 2010

\section{REFERENCES}

1. Wang, M.-Y. et al. Proc. Natl. Acad. Sci. USA; published online March 1, 2010; doi:10.1073/pnas.0909422107

Contact: Roger Unger, Touchstone Diabetes Center, The University of Texas Southwestern Medical Center at Dallas, Dallas, Texas e-mail: roger.unger@utsouthwestern.edu

2. Yu, X. et al. Proc. Natl. Acad. Sci. USA 105,14070-14075 (2008)

3. Morioka, T. et al. J. Clin. Invest. 117, 2860-2868 (2008)

\section{COMPANIES AND INSTITUTIONS MENTIONED}

Amgen Inc. (NASDAQ:AMGN), Thousand Oaks, Calif. Amylin Pharmaceuticals Inc. (NASDAQ:AMLN), San Diego, Calif. Joslin Diabetes Center, Boston, Mass.

Takeda Pharmaceutical Co. Ltd. (Tokyo:4502), Osaka, Japan University of Miami, Coral Gables, Fla.

The University of Texas Southwestern Medical Center at Dallas, Dallas, Texas 